\title{
The Effect of Workload Perception and Occupational Stress on Medical Error Attitudes of Nurses Working in Surgical Clinics
}

\author{
Yasemin Özyer ${ }^{1}$, Nurgül Bölükbaş², Dilek Çilingir ${ }^{3}$ \\ ${ }^{1}$ Sinop University, Duragan Vocational School, Duragan, Sinop, Turkey \\ ${ }^{2}$ Ordu University, Faculty of Health Sciences, Department of Surgery Nursing, Ordu, Turkey \\ ${ }^{3}$ Karadeniz Technical University, Faculty of Health Sciences, Department of Surgery Nursing, Trabzon, Turkey \\ Received: 25 September 2019, Accepted: 31 March 2020, Published online: 30 April 2020 \\ (C) Ordu University Institute of Health Sciences, Turkey, 2020
}

\begin{abstract}
Objectives: The study was conducted to determine workload perception and effects of occupational stress on medical error attitudes of nurses working in surgical clinics.

Method: This descriptive study was conducted with 100 nurses employed at surgery clinics, Ordu State Hospital and Training and Research Hospital of Ordu University, Turkey. The data were collected using Descriptive Questionnaire Form, Occupational Stress Scale, Individual Workload Perception Scale and Medical Error Attitudes Scale between September and December 2015.

Results: There is not any significant relationship between the average scores of all three scales when they are compared with each other ( $p>0.05)$. The surgical nurses' average score on the individual workload perception scale is $73.37 \pm 9.06$, their average score on the occupational stress scale is $42.21 \pm 4.99$, and their average score on the medical error attitude scale is $40.86 \pm 5.40$. It was determined that workload perception and occupational stress in the nurses employed in surgical clinics did not have effect on the medical error attitudes. ( $\mathrm{r}=0.712)$.

Conclusion: In this study, it was observed that nurses' perception of work stress and work overload did not affect medical error attitudes. The overall average scores of surgical nurses on the scales of individual workload perception, occupational stress, and medical error attitude are directly proportional.
\end{abstract}

Key words: Nursing care, occupational stress, medical error attitudes, overload, surgical patient, surgical nurse

Suggested Citation: Ozyer Y, Bolukbas N, Cilingir D. The Effect of Workload Perception and Occupational Stress on Medical Error Attitudes of Nurses Working in Surgical Clinics. Middle Black Sea Journal of Health Science, 2020; 6(1):6-17

\section{Address for correspondence/reprints:}

Nurgül Bölükbaş

Telephone number: +90 (555) 0205152

ORCID-ID 0000000156848359

E-mail: nurbol_52@hotmail.com

DOI: $\quad 10.19127 /$ mbsjohs. 624390

Note: This study is presented as a thesis

\section{Introduction}

Nowadays, medical errors rank definitely first among the issues occupying the health care sector most. Medical errors are one of the important issues emphasized in Turkey like other countries around the world. One of the basic causes of this issue's significance is primarily about human life and human health. The errors made intentionally or unintentionally threaten a human's life. The suspension of practices, knowledge and skill deficiency of healthcare employees, wrong practices, intense workload, inadequacy in patient care and 
communication between team members spring from medical (Hillin and Hicks, 2010, Nguyen et al, 2010).

Medical error should be defined exactly first of all, in order to reduce the damages emanated from medical errors. The Joint Commission on Accreditation of Healthcare Organizations (JCAHO) defines the medical error term as "unethical and inappropriate behavior of a professional offering healthcare, his/her negligence and deficiency in professional practices that lead patient to suffer (JCAHO, 2006). Stress due to working conditions and heavy workload in nursing play role in the occurrence of insufficiency and negligence in professional practices. In a resource regarding this issue, it was found that 1200 people died because of wrong drugs administration in the United Kingdom in 2001 (Indepeler and Dursun, 2012). After examining 33 documents about wrong drug administration, it was underlined that it is required to be careful while administering or preparing drug for patients in order to prevent wrong drug errors (Wright, 2010). Wrong dose $(36.1 \%)$ and wrong drug $(26.4 \%)$ errors place in the first rank of the most common wrong drug errors (Tang et al, 2007).

Medical errors may appear at any stage of health care. These errors can be classified under the titles below Wrong drug errors, surgical errors, diagnostic errors, errors related to system deficiencies and others which some important issues such as hospital infections and wrong blood transfusion are also among the medical errors (Sayek, 2011).

Nurses comprising the majority of medical professionals encounter the risk of medical errors more frequently than other professional groups, because of the multitude and variety of dependent and independent functions, and the continuity of their relationship with patient relatives (Tang et al, 2007, Anezz, 2006). Determination of medical errors made by medical professionals may enable to detect the source of errors and catch and correct an error before it reaches any patient (Anderson et al, 2009).

Workload of nursing can be defined as total nursing care required to be performed within a fixed period of time. Some of the factors affecting the workload in nursing care are the features of the related unit, the number of patients offered care, the knowledge and skill level of nurses in charge (Er and Altuntas, 2016). The technological circumstances of developing world are increasing the workload. Consequently, it results in the rise of occupational stress (Aytac, 2002). Among the causes increasing the occupational stress of nurses, there are intense work pace, patient care, supporting patients physically, socially, and psychologically, constant connection with patient relatives, and administrative problems (Kebapc1 and Akyolcu, 2011).

The direct involvement of nurses in patient care and being constantly together with patients and patient relatives are among the factors increasing the health risk (Karwowski et al, 2005, Parlar, 2008, Mollaoğlu et al, 2010). The negative working conditions of nurses, staying up continuously, and night duty are among the factors increasing the health risks (Parlar, 2008, Alcelik et al, 2005).

Nurses being occupied with something else while administering a drug, new patient registrations, and heavy workload may pave the way for medical errors (Gunes et al, 2014). It was detected that $91.7 \%$ of nurses make error due to events distracting them (such as answering the phone), $43.7 \%$ of them due to the problems in material conditions (Eser and Khorshid, 2007). The relationship between work stress, work overload and medical error should be briefly addressed.

This study with the aim of identifying the workload perception of nurses, their occupational stress and its effects on the medical error attitude of nurses conducted or carry out.

\section{Methods}

\section{Study Subjects and Design}

This study is a descriptive research. This study was conducted between September and December 2015, with nurses employed at general surgery, urology, neurosurgery, cardiovascular surgery, orthopedics and traumatology in the clinics at Ordu State Hospital and Training and Research Hospital of Ordu University.

\section{Data Collection Tools}

A Nurse Identification Form was constructed by the researchers based on the literature and included identifying characteristics of the participants.

Occupational Stress Scale: This scale was developed by Revicki et al. In 1991, and its validity and reliability were validated by Aslan et al. In 1996 and adapted into Turkish (Aslan et al,1998). The Occupational Stress Scale consists of 18 items and has 4-point Likert-type and no subscales. Items 2, 4, $8,9,11,15$ of the scale are scored in reverse. The highest score is 72 and the lowest score is 18 . Occupational Stress Scale increases as the score from the scale increases. In Aslan's study, the Cronbach's alpha value was 0.78 and the original scale was 0.85 0.90. In our study, Cronbah Alpha value was found to be 0.698 . 
Individual Workload Perception Scale: The validity and reliability of the scale were performed by Cox et al in 2003 and Turkey also made the validity and reliability study of the scale of Saygili (Saygili and Celik, 2011). In the study conducted by Cox et al., Cronbach's alpha value was found to be 0.87 in the administrative support dimension, 0.84 in the peer support dimension, 0.66 in the unit support dimension, 0.75 in the workplace workload dimension, and 0.86 in the intention to continue the current job (Cox et al., 2007). In our study, Cronbach's alpha value was found to be 0.667 .

The Individual Workload Perception Scale consists of executive support, colleague support, unit support, work environment workload features and existing job resume sub-dimensions. The scale consists of 31 questions, Consisting of 5 subdimensions and 5 of the five-point Likert-type. The lowest score is 31 and the highest score is 155 . The increase in the average of the intention to pursue the current job indicates that the intention to pursue the current job is low. The increase in the other sub-neck averages is perceived positively.

Medical Error Attitudes Scale: The scale was developed by Gulec and Indepeler (Gulec, 2013). The scale is 16 items and has a five likert type. The lowest score is 16 and the highest score is 80 . The medical error behaviors of the employees who scored 38-40 points in the scale are negative, and the medical error attitudes of the areas over this score are evaluated as positive. The Cronbach's alpha reliability coefficient of the MEAS has been reported as .75; in this study, it was found to be .66 .

\section{Data Collection}

Data were collected by the nurses themselves using face to face interview technique. Nurses work at the clinics for 40 hours minimum per week between 08:00-16:00 or 16:00-08:00 with 8 and 16 hours shifts changing weekly.

\section{Data Analysis}

The data were analyzed by computer. Data were evaluated using percentages, mean values, arithmetic mean. In these statistical comparisons, the control for the normal distribution of data was conducted by Kolmogorov-Smirnov test, and the homogeneity control of group variances by Levene test. As of parametric tests, one-way ANOVA, Tukey multiple comparison test and $t$ test were used in comparing the averages of data validating the hypotheses. As of nonparametric tests, Kruskal-Wallis test, Mann Whitney $\mathrm{U}$ and Dunn multiple comparison test were used for the data not validating the hypotheses.
Cronbach Alfa values were calculated for the reliability analysis of the scales. In analyzing the differences between the groups, the significance level was set as 0.05 .

\section{Results}

$91 \%$ of the nurses involved in the study are female and $9 \%$ male. $76 \%$ of the nurses are married and $22 \%$ single and $2 \%$ separated from spouse. $22 \%$ of 100 nurses, married or separated has 3 or more children, while $53 \%$ of them less than three children. $44 \%$ of nurses graduated from associate' degree, $42 \%$ of them have an undergraduate degree. The age average of nurses is $36.63 \pm 7.69$. (min:19, $\max : 55$ ).

$56 \%$ of nurses tell that they have a dependent relative. $90 \%$ of nurses are surgical clinic nurse, $53 \%$ of surgical nurses work willingly and $30 \%$ partly willingly. $41 \%$ of nurses express that they find their salary insufficient. $57 \%$ of them express that she is able to take legal leave. $20 \%$ of them work on a permanent day shift basis and $66 \%$ on a rotating day and night basis. $60 \%$ of them have 4-6 night duty in average per month. The length of service of $42 \%$ of nurses is between $11-20$ years, $31 \%$ of nurses have a length of service at the institution between 2-5 years, $25 \%$ of them have that between $0-1$ year and $34 \%$ of nurses take care of 7-10 patients a day.

On Table 1, the comparison of average scores on the scales of individual workload perception, occupational stress, and medical error attitude according to the descriptive attributes of nurses can be observed. Any significant association cannot be found between the scales of individual workload perception, occupational stress, medical error attitude and the age, sex, marital status, number of children, educational status, existence of dependents, salary satisfaction, taking official leaves ( $p>0.05$ ). The score of surgical nurses, working unwillingly at their clinics on the occupational stress scale (43.29 \pm 6.46$)$ is found significantly higher than that of the nurses working willingly $(39.6 \pm 5.10)$ and partly willingly (41.70 \pm 4.76$)$. A significant difference is discovered between the average score of surgical nurses on the scale of occupational stress and the willingness to work at the related clinic $(\mathrm{p}=0.037)$, (Table 1$)$.

There is no significant difference between the average scores on the scales of individual workload perception, occupational stress, medical error attitude and the work unit, assignment, working pattern, monthly average number of night duty, length of service at the institution, daily number of patients taken care ( $p>0.05)$, (Table 1). 
Table 1. Comparison of Personal Characteristics and Scale Score Average of Nurses

\begin{tabular}{|c|c|c|c|c|}
\hline $\begin{array}{l}\text { Descriptive } \\
\text { Characteristics }\end{array}$ & $\mathbf{S}$ & $\begin{array}{c}\text { Workload } \\
\text { Perception } \\
\mathbf{X} \pm \text { SD }\end{array}$ & $\begin{array}{l}\text { Occupational Stress } \\
\qquad \mathbf{X} \pm \mathbf{S D}\end{array}$ & $\begin{array}{c}\text { Medical Error } \\
\text { Attitude Scale } \\
\quad \mathbf{X} \pm \text { SD }\end{array}$ \\
\hline \multicolumn{5}{|l|}{ Age groups } \\
\hline Age average of nurses & $36.63 \pm 7.69$ & & & \\
\hline $19-30$ years & 21 & $73.38 \pm 9.80$ & $41.52 \pm 6.33$ & $40.48 \pm 3.68$ \\
\hline $31-40$ years & 48 & $73.00 \pm 8.67$ & $40.50 \pm 4.90$ & $42.77 \pm 5.81$ \\
\hline \multirow{3}{*}{$41-55$ years } & 31 & $73.94 \pm 9.40$ & $40.97 \pm 5.59$ & $42.52 \pm 4.18$ \\
\hline & & $\mathrm{H}=0.051$ & $\mathrm{H}=0.355$ & $\mathrm{H}=4.58$ \\
\hline & & $\mathrm{p}=0.975$ & $\mathrm{p}=0.837$ & $p=0.101$ \\
\hline \multicolumn{5}{|l|}{ Gender } \\
\hline Female & 91 & $72.97 \pm 9.12$ & $40.98 \pm 5.50$ & $42.36 \pm 4.97$ \\
\hline \multirow[t]{3}{*}{ Male } & 9 & $77.44 \pm 7.65$ & $39.65 \pm 4.24$ & $40.67 \pm 5.17$ \\
\hline & & $\mathrm{Z}=-1.52$ & $\mathrm{Z}=-0.525$ & $Z=-0.815$ \\
\hline & & $\mathrm{p}=0.129$ & $\mathrm{p}=0.601$ & $\mathrm{p}=0.415$ \\
\hline \multicolumn{5}{|l|}{ Marital status } \\
\hline Married & 76 & $73.04 \pm 9.67$ & $40.83 \pm 5.17$ & $42.20 \pm 4.92$ \\
\hline \multirow{3}{*}{ Single } & 24 & $74.42 \pm 6.83$ & $40.96 \pm 6.17$ & $42.25 \pm 5.31$ \\
\hline & & $Z=-0.186$ & $Z=-0.222$ & $\mathrm{Z}=-0.291$ \\
\hline & & $\mathrm{p}=0.853$ & $\mathrm{p}=0.824$ & $\mathrm{p}=0.771$ \\
\hline \multicolumn{5}{|l|}{ Number of children $(n=76) *$} \\
\hline$<3$ Children & 41 & $73.85 \pm 9.09$ & $40.81 \pm 5.67$ & $42.04 \pm 4.63$ \\
\hline$\geq 3$ Children & 17 & $73.05 \pm 8.91$ & $40.36 \pm 4.05$ & $43.23 \pm 5.50$ \\
\hline \multirow[t]{3}{*}{ No Child } & 18 & $72.64 \pm 9.43$ & $41.40 \pm 5.97$ & $41.68 \pm 5.32$ \\
\hline & & $\mathrm{H}=0.569$ & $\mathrm{H}=0.269$ & $\mathrm{H}=2.41$ \\
\hline & & $\mathrm{P}=0.752$ & $\mathrm{p}=0.874$ & $p=0.301$ \\
\hline \multicolumn{5}{|l|}{ Education status } \\
\hline High School & 11 & $76.55 \pm 5.94$ & $41.00 \pm 7.33$ & $41.55 \pm 4.32$ \\
\hline Associate degree & 44 & $72.16 \pm 9.76$ & $41.86 \pm 5.07$ & $41.73 \pm 5.31$ \\
\hline \multirow[t]{3}{*}{ Undergraduate and Graduate } & 45 & $73.78 \pm 8.91$ & $39.84 \pm 5.11$ & $42.84 \pm 4.83$ \\
\hline & & $\mathrm{H}=1.57$ & $\mathrm{H}=3.31$ & $\mathrm{H}=1.01$ \\
\hline & & $\mathrm{p}=0.455$ & $\mathrm{p}=0.191$ & $p=0.604$ \\
\hline \multicolumn{5}{|l|}{ Existence of dependants } \\
\hline Yes & 56 & $74.25 \pm 8.63$ & $40.71 \pm 5.24$ & $42.46 \pm 5.11$ \\
\hline \multirow[t]{3}{*}{ No } & 44 & $72.25 \pm 9.56$ & $41.05 \pm 5.64$ & $41.89 \pm 4.87$ \\
\hline & & $z=-0.977$ & $\mathrm{z}=-0.251$ & $\mathrm{z}=-0.941$ \\
\hline & & $\mathrm{p}=0.329$ & $\mathrm{p}=0.802$ & $\mathrm{p}=0.347$ \\
\hline \multicolumn{5}{|l|}{ Willingness to work } \\
\hline Yes & 53 & $74.60 \pm 9.15$ & $39.60 \pm 5.10$ & $43.00 \pm 5.29$ \\
\hline No & 17 & $72.00 \pm 8.55$ & $43.29 \pm 6.46$ & $42.00 \pm 4.77$ \\
\hline \multirow[t]{3}{*}{ Partially } & 30 & $71.97 \pm 9.16$ & $41.70 \pm 4.76$ & $40.93 \pm 4.39$ \\
\hline & & $\mathrm{H}=1.555$ & $\mathrm{H}=6.591$ & $\mathrm{H}=3.012$ \\
\hline & & $\mathrm{p}=0.459$ & $\mathbf{p}=\mathbf{0 . 0 3 7}$ & $\mathrm{p}=0.222$ \\
\hline \multicolumn{5}{|l|}{ Salary satisfaction } \\
\hline Sufficient & 6 & $73.17 \pm 7.52$ & $40.17 \pm 4.26$ & $40.67 \pm 5.39$ \\
\hline Partly Sufficient & 35 & $74.83 \pm 8.74$ & $40.34 \pm 5.14$ & $42.51 \pm 5.80$ \\
\hline Insufficient & 41 & $72.39 \pm 8.64$ & $40.12 \pm 5.02$ & $42.63 \pm 4.86$ \\
\hline \multirow[t]{3}{*}{ Quite Insufficient } & 18 & $72.83 \pm 11.21$ & $43.78 \pm 6.42$ & $41.17 \pm 3.29$ \\
\hline & & $\mathrm{H}=2.958$ & $\mathrm{H}=5.458$ & $\mathrm{H}=2.622$ \\
\hline & & $\mathrm{p}=0.398$ & $\mathrm{p}=0.141$ & $\mathrm{p}=0.454$ \\
\hline \multicolumn{5}{|l|}{ Taking official leave } \\
\hline Yes & 57 & $73.93 \pm 8.95$ & $41.05 \pm 5.65$ & $41.89 \pm 5.70$ \\
\hline \multirow{3}{*}{ No } & 43 & $72.63 \pm 9.25$ & $40.60 \pm 5.10$ & $42.63 \pm 3.87$ \\
\hline & & $Z=-1.108$ & $Z=-0.464$ & $Z=-0.409$ \\
\hline & & $\mathrm{p}=0.268$ & $\mathrm{p}=0.643$ & $\mathrm{p}=0.683$ \\
\hline
\end{tabular}


Table 2. Comparison of Working Characteristics of The Nurses and The Mean Scale Score

Workload Occupat

\section{Work unit}

Cardiovascular Surgery Service

Plastic+ Neurosurgery Service

Urology+ Thoracic Surgery Service

General Surgery Service

Orthopedics Service

Pediatric + General Surgery Service

ENT+ Eye Service

All Surgery Services

\section{Assignment \\ Head of Clinic}

Clinic Nurse

\section{Working pattern}

\section{Permanent Day Shift}

Permanent Night Shift

All-Total

\section{Monthly average number of night shift}

\author{
1-3 duty \\ 4-6 duty \\ 7-10 duty \\ No Duty
}

\section{Total length of service}

$$
\begin{aligned}
& 0-1 \text { year } \\
& 2-5 \text { years } \\
& 6-10 \text { years } \\
& 11-20 \text { years } \\
& 21-35 \text { years }
\end{aligned}
$$

\section{Length of service at the institution}

$$
\begin{aligned}
& \text { 0-1years } \\
& \text { 2-5years } \\
& \text { 6-10years } \\
& \text { 11-20years } \\
& \text { 21-35 years }
\end{aligned}
$$

\section{Daily number of patients taken care}

$$
\begin{aligned}
& \text { 1-3 patients } \\
& \text { 4-6 patients } \\
& \text { 7-10 patients } \\
& \text { 11-14 patients } \\
& \text { 15-25 patients }
\end{aligned}
$$

$\mathbf{S}$

16

10

12

10

10

11

8

23

10

90

14

66

17

60

17

6

$\mathrm{H}=3.87$

$\mathrm{p}=0.276$

$78.50 \pm 8.07$

$75.19 \pm 4.71$

$69.25 \pm 12.51$

$71.52 \pm 9.63$

$74.92 \pm 8.57$

$\mathrm{H}=5.7$

$\mathrm{p}=0.223$

$74.24 \pm 9.96$

$72.90 \pm 8.60$

$71.78 \pm 9.07$

$75.14 \pm 8.31$

$74.00 \pm 10.74$

$\mathrm{H}=1.587$

$\mathrm{p}=0.811$

$74.00 \pm 6.18$

$72.17 \pm 7.23$

$72.71 \pm 11.41$

$70.83 \pm 9.33$

$74.71 \pm 8.31$

$\mathrm{H}=1.755$

$\mathrm{p}=0.781$

\begin{tabular}{c}
$\begin{array}{c}\text { Occupational } \\
\text { Stress } \\
\mathbf{X} \pm \text { SD }\end{array}$ \\
\hline $40.31 \pm 4.80$ \\
$43.00 \pm 7.09$ \\
$43.58 \pm 5.74$ \\
$39.00 \pm 6.63$ \\
$40.10 \pm 5.38$ \\
$39.73 \pm 4.43$ \\
$39.38 \pm 5.40$ \\
$41.09 \pm 4.54$ \\
$\mathrm{H}=7.51$ \\
$\mathrm{p}=0.378$
\end{tabular}

$39.90 \pm 4.20$

$40.97 \pm 5.52$

$\mathrm{z}=-0.345$

$\mathrm{p}=0.731$
$39.40 \pm 3.95$
$42.86 \pm 6.11$
$40.88 \pm 5.55$
$\mathrm{H}=2.542$
$\mathrm{p}=0.281$
$40.41 \pm 4.40$
$41.13 \pm 5.76$
$41.00 \pm 5.62$
$39.00 \pm 4.10$
$\mathrm{H}=0.679$
$\mathrm{p}=0.878$

$40.88 \pm 5.25$

$41.06 \pm 6.14$

$40.13 \pm 4.12$

$41.19 \pm 5.43$

$40.42 \pm 5.60$

$\mathrm{H}=0.357$

$\mathrm{p}=0.986$

$41.00 \pm 5.24$

$39.84 \pm 4.68$

$41.61 \pm 6.53$

$42.00 \pm 5.88$

$40.14 \pm 4.30$

$\mathrm{H}=1.684$

$\mathrm{p}=0.794$

$40.59 \pm 6.17$

$40.42 \pm 4.25$

$41.21 \pm 5.13$

$39.17 \pm 4.02$

$41.13 \pm 6.05$

$\mathrm{H}=1.025$

$\mathrm{p}=0.906$
Medical Error

Attitude Scale

$\mathbf{X} \pm \mathbf{S D}$

$43.50 \pm 5.22$

$40.20 \pm 3.91$

$41.67 \pm 5.37$

$42.70 \pm 5.25$

$42.90 \pm 4.77$

$42.82 \pm 7.90$

$42.38 \pm 3.20$

$41.61 \pm 4.04$

$\mathrm{H}=4.53$

$\mathrm{p}=0.717$

$42.70 \pm 5.12$

$42.16 \pm 5.00$

$\mathrm{z}=-0.432$

$\mathrm{p}=0.666$

$41.25 \pm 5.00$

$40.36 \pm 3.93$

$42.89 \pm 5.09$

$\mathrm{H}=4.31$

$\mathrm{p}=0.116$

$41.65 \pm 5.59$

$42.58 \pm 5.31$

$41.53 \pm 4.05$

$42.00 \pm 1.67$

$\mathrm{H}=0.732$

$\mathrm{p}=0.866$

$40.63 \pm 3.62$

$38.94 \pm 4.64$

$42.50 \pm 5.13$

$43.57 \pm 5.45$

$42.42 \pm 3.87$

$\mathrm{H}=10.829$

$\mathrm{p}=0.029$

$41.36 \pm 6.26$

$42.68 \pm 4.64$

$42.30 \pm 4.35$

$42.29 \pm 4.53$

$42.71 \pm 5.19$

$\mathrm{H}=1.636$

$\mathrm{p}=0.802$

$43.12 \pm 6.37$

$42.67 \pm 5.30$

$41.50 \pm 4.97$

$43.17 \pm 2.04$

$42.13 \pm 4.57$

$\mathrm{H}=11.055$

$\mathrm{p}=0.901$ 
The average score of surgical nurses, with a length of service between 2-5 years, on the medical error attitude scale is $38.94 \pm 4.64$, that of the nurses with a length of service between $11-20$ years $43.57 \pm 5.45$. A statistically significant difference is detected between the total length of service of surgical nurses and their average score on the medical error attitude scale $(\mathrm{p}=$ 0.029). Also, the difference between the average scores on the scales of individual workload perception, and occupational stress and the total length of service is not statistically significant ( $>>0.05$ ), (Table 2).

Any statistically significant different is not found between the surgical nurses' average scores on the scales of individual workload perception, occupational stress, and medical error attitude and their responses to the questions "have you ever made at least one error jeopardizing the patient safety during your length of service?" and "have you ever seen any error of your team mates jeopardizing the patient safety?" ( $p>0.05)$, (Table 2$)$.

On Table 3, the average scores on the subdimensions of individual workload perception scale are displayed. A significant correlation is found between the average scores on the individual workload perception scale's sub-dimensions are manager support, peer support, unit support, and work environment- and the total average scores of individual workload perception $(\mathrm{p}<0.05)$. On the other hand, no significant association is observed between the intent to keep the present job and the total average scores on the scale of individual workload perception $(p>0.05)$. As the score on the subdimension of manager support increases, the scores on the sub-dimensions of peer support and unit support increase. When the unit's support increases, the score on work environment also increases (Table $3)$.

On Table 4, the comparison of the average scores on the scales of individual workload perception, occupational stress, and medical error attitude is displayed. The surgical nurses' average score on the individual workload perception scale is $73.37 \pm 9.06$, their average score on the occupational stress scale is $42.21 \pm 4.99$, and their average score on the medical error attitude scale is $40.86 \pm 5.40$. Any significant association is not detected between the average scores on the scales of individual workload perception, occupational stress, and medical error attitude (p>0.05), (Table 4).

No statistically significant association is found between the scales of individual workload perception, occupational stress, and medical error attitude. (p>0.05), (Table 5).

Table 3. Association Between Average Scores on The Sub-Dimensions of Individual Workload Perception Scale

\begin{tabular}{|c|c|c|c|c|}
\hline $\begin{array}{l}\text { Sub-dimensions of Individual Workload } \\
\text { Perception Scale }\end{array}$ & $\begin{array}{l}\text { Average Scores } \\
\quad \mathbf{X} \pm \mathbf{S S}\end{array}$ & Min. Max. & $\mathbf{p}$ & $\mathbf{r} *$ \\
\hline Manager Support & $17.49 \pm 4.18$ & $6-26$ & 0.000 & $-0.712 * * *$ \\
\hline Peer Support & $26.85 \pm 5.32$ & $14-40$ & 0.000 & $-0.685^{* * *}$ \\
\hline Unit Support & $5.37 \pm 2.21$ & $2-10$ & 0.000 & $-0.410 * * *$ \\
\hline Work Environment & $14.47 \pm 2.77$ & $5-21$ & 0.004 & $-0.287 * * *$ \\
\hline Intent to Keep the Present Job & $9.19 \pm 1.96$ & $6-15$ & 0.283 & -0.108 \\
\hline $\begin{array}{l}\text { Overall average score on individual workload } \\
\text { perception scale }\end{array}$ & $73.37 \pm 9.06$ & 40- 94 & $\begin{array}{l}0.419 \\
- \\
\end{array}$ & -0.082 \\
\hline
\end{tabular}

*r: Pearson korelasyon analizi

$* * * \mathrm{p}<0.01$ 
Table 4. Comparison of Average Score of Individual Workload Perception Scale, Occupational Stress Scale, And Medical Error Attitudes Scale

\begin{tabular}{llcc}
\hline Scales & $\begin{array}{l}\text { Average Scores } \\
\mathbf{X} \pm \mathbf{S S}\end{array}$ & Min. - Max. & p \\
\hline Individual Workload Perception Scale & $73.37 \pm 9.06$ & $31-155$ & 0.419 \\
Occupational Stress Scale & $42.21 \pm 4.99$ & $18-72$ & 0.168 \\
Medical Error Attitude Scale & $40.86 \pm 5.40$ & $16-80$ & 0.084 \\
\hline
\end{tabular}

Table 5. Association Between Score on the Scales of Individual Workload Perception, Occupational Stress and Medical Error Attitude Scale the Surgical Nurses'

\begin{tabular}{|c|c|c|c|c|c|c|}
\hline & \multicolumn{2}{|c|}{$\begin{array}{l}\text { Medical Error } \\
\text { Scale Attitude Scale }\end{array}$} & \multicolumn{2}{|c|}{$\begin{array}{c}\text { Occupational } \\
\text { Stress Scale }\end{array}$} & \multicolumn{2}{|c|}{$\begin{array}{l}\text { Individual Workload } \\
\text { Perception Scale }\end{array}$} \\
\hline & $\mathbf{r}$ & $\mathbf{p}$ & $\mathbf{r}$ & $\mathbf{p}$ & $\mathbf{r}$ & p \\
\hline Individual Workload & .082 & .419 & .174 & .084 & - & - \\
\hline \multicolumn{7}{|l|}{ Perception Scale } \\
\hline Medical Error & - & - & -139 & .168 & -.052 & .187 \\
\hline \multicolumn{7}{|l|}{ Attitude Scale } \\
\hline Occupational Stress Scale & -069 & .152 & - & - & -066 & .276 \\
\hline
\end{tabular}

r: Pearson Correlation Analysis

\section{Discussion}

Any statistically significant difference is not identified between the average scores on the scales of individual workload perception, occupational stress, and medical error attitude and the variable of age. Like our study, Cebeci (2012) ascertained in the study on nurses that the age variable has not any impact on the proneness to make a medical error. No statistically significant difference is discovered among the scales of individual workload perception, occupational stress, and medical error attitude and the sex variable. Yigitsoy (2014) pointed out in the study on nurses that the sex variable affects the medical error. Similarly, to our study, Tel et al (2012) found that the sex variable does not result in any significant difference in the scores of occupational stress. No statistically significant difference is identified between the average scores on the scales of individual workload perception, occupational stress, and medical error attitude and the marital status. Arikan and Karabulut (2004), Ercevik (2010) and Kopuz (2013) stated also in their studies that the occupational stress is not affected by the marital status. Mohsen, Marzieh and Negin (2012) stated nurses' experiences, the following items were some of the stress factors for the nurses: lack of experience, poor social status, lack of proper logistics, nurse shortages, irregularities in the organization, managers' poor performance, colleagues' poor relations, and patients' conditions.

No statistically significant difference is discovered between the scales of individual workload perception, occupational stress, and medical error attitude and the number of nurses' children. Kopuz (2013) and Ercevik (2010) expressed in their studies that as the number of children increases, the occupational stress decreases. In the study of Arikan and Karabulut (2004) it was ascertained that the occupational stress is not affected by the number of children.

Any statistically significant difference is not found between the average scores on the scales of individual workload perception, occupational stress, and medical error attitude and the educational status and the existence of surgical nurses' dependent. However, Yang et al. (2017) found that education had a negative relationship with job stress, namely, that nurses with higher levels of education had lower levels of perceived job stress. Tunaligil (2013) pointed out in the study on Emergency Medical Technicians that the educational status and the number of persons in the household do not have any impact on the occupational stress. This result is similar to our study (Eroglu, 2011).

The scores of the nurses, working unwillingly at their clinics, on the occupational stress scale is found 
statistically significantly higher than those of the nurses working willingly or partly willingly. Eroglu (2011) discovered in the study on nurses that the burnout level of the nurses working willingly is lower. This finding leads to think that the professional satisfaction of the nurses working willingly is high and their occupational stress is less, thus. Likewise, it can be deduced that the nurses with higher professional satisfaction and lower occupational stress have a higher awareness about the medical error attitude.

Any statistically significant difference is not identified between the average scores on the scales of individual workload perception, occupational stress, and medical error and the salary satisfaction of surgical nurses. Unlike our study, Kopuz (2013) determined in her study that the nurses dissatisfied with their salary have a higher occupational stress.

No statistically significant difference is detected between the average scores on the scales of individual workload perception, occupational stress, and medical error attitude and the surgical nurses' state of taking legal leave. Eroglu (2011) found in the study on nurses that the nurses do not encounter any problem in taking legal leave. This result is similar to that of our study.

No significant difference is found between the average scores on the scales of individual workload perception, occupational stress, and medical error attitude and the work units. Differently from our study, Dikmen et al (2014) determined in their study on nurses that the work units (surgical clinics) have an impact on the probability of making medical error. Dagget, Molla and Belachew (2016) in this study; working unit/department particularly working in the chronic illness follow-up clinic, mutual understanding at work between nurse, physician and job satisfaction were predictor variables for overall job related stress. This finding may result from the similarity between the physical conditions, work intensity, and the number of working nurses at the surgical clinics where the study was conducted.

Any statistically significant difference is not discovered between the average scores on the scales of individual workload perception, occupational stress, and medical error and the assignment. Unlike our study, Tel et al (2012) stated in their study that the occupational stress level of clinical nurses is higher than that of clinic head nurses. It can be thought that the limited number of nurses working as the head of clinic in our study leads to this result.

The average scores of the surgical nurses, working permanent night shift, on the scales of individual workload perception $(72.29 \pm 10.02)$ and occupational stress $(40.88 \pm 5.55)$ are lower but their scores on the medical error attitude scale (42.89 \pm 5.09$)$ are higher. Any statistically significant difference is not discovered between the working pattern of surgical nurses and their average scores on the scales of individual workload perception, occupational stress, and medical error attitude. Hughes and Ortiz (2005) pointed out in their study that the shift work increases the incidence of making medical error. Hongxia et al (2019) found that shift work impinged on quality of life; some researchers reported shift work as an important cause of long-term stress, particularly for those involving night duty rotations. Although any statistical difference is not found in our study, the occupational stress, individual workload perception, and medical error attitude have a directly proportional trend.

Any statistically significant difference is not found between the monthly average number of night duty and the average scores of surgical nurses on the scales of individual workload perception (75.67 \pm 7.17$)$, occupational stress $(41.13 \pm 5.76)$, and medical error attitude (75.67 \pm 7.17$)$. While the individual workload perception of surgical nurses with no night duty is higher, the average scores of surgical nurses, being on duty 4-6 times a month, on the scales of occupational stress and medical error attitude are higher.

Ercevik (2010) and Kopuz (20139 stated in their study that the nurses working in shifts and with more weekly work hours have a higher occupational stress. The causal mechanism behind this result can be considered that the nurses being on night duty 4-6 times a month have to work daily in order to complete weekly work hours, which is 40 hours, and it leads to increase their workload perception and occupational stress, and a negative medical error attitude, thus.

A statistically significant difference is identified between the nurses' total length of service and their average score on the medical error attitude scale. The overall average scores of the nurses -working 6 months-1 year and 2-5 years in surgical clinics- on the medical error scale are statistically significantly lower than those of nurses working 6-10 years, 11-20 years, and 21-35 years. Unlike our study, Parshuram et al (2008) ascertained that the nurses working more than 10 years make less medical error. Sheu et al (2008) discovered in their study that $53.7 \%$ of nurses have less than 2 years of professional experience and $31.1 \%$ of nurses have 25 years; the nurses with little or no experience make more medical error. Balcik (2013) determined in her study that the nurses working less than five years have more occupational stress. This finding may be interpreted that while the nurses working less than five years' experience more 
occupational stress and medical error, they do not behave in an self-confident and brave manner due to their inexperience.

No statistically significant difference is detected between the number of patients taken care by surgical nurses and the average scores of nurses on the scales of individual workload perception, occupational stress, and medical error attitude. Differently from our study, Ercevik (2010) discovered in the study that as the number of patients rises, the occupational stress of nurses rises. This result can be explained by the fact that as the number of patients per nurse increases, the support of units such as secretariat, physiotherapy, social service expert increases at the institution the study was conducted.

Any statistically significant difference is not identified between the average scores of nurses on the scales of individual workload perception, occupational stress, and medical error attitude and their state of making at least one error jeopardizing the patient safety during their length of service. In the research conducted by Ozata and Altunkan (2010), $93.8 \%$ of nurses responded as "No" to this question. Our study is in accordance with the literature.

The average score of surgical nurses, participating in our study, on the individual workload perception scale is $73.37 \pm 9.06$. Considering the fact that the scale ranges between 31 and 155, this result demonstrates that the surgical nurses' individual workload perception is within the normal level. Tan et al (2012) determined in their study that the working environment perception of nurses is high. Our study results are not similar to the literature (Cox. 2007).

The average score of nurses, participating in our study, on the scale of occupational stress is $40.86 \pm$ 5.40. Regarding the fact that the scale ranges from 18 to 72 , the surgical nurses experience the occupational stress at the medium level. Kopuz (2013) found in her study the score of nurses on the occupational stress scale as $38.89 \pm 8.92$. In the study done by Ercevik (2010) the occupational stress score of nurses is 40.77 \pm 682 . Our study is in accordance with the literature (Ayaz and Beydag, 2014).

The average score of nurses, participating in our study, on the scale of medical error attitude is $42.21 \pm$ 4.99. Considering the fact that the scale of medical error attitude ranges from 16 to 80 , the scores of surgical nurses on the medical error attitude scale is at the medium level. Güleç21 ascertained that the nurses are more positive in reporting the medical error in case a medical error is made. Dikmen et al (2014) and Cebeci et al (2012) expressed in their studies on nurses that their score of proneness to medical error is low. Our study is not similar to the literature at this point.

The highest correlation of total score on the individual workload perception scale is with the score of manager support. After that, the peer support score, unit support and working environment support score are correlated respectively. No significant association is found between the intent to keep the present job and the total score on the individual workload perception scale.

The analysis of individual workload perception scale's sub-dimensions demonstrates that the nurses perceive the peer support more positive. Then, the manager support, working environment perception, unit support, and the intent to keep the present job come respectively. Cox (2007), Saygili and Celik (2011) stated, in their studies on pediatric nurses and medical professionals respectively, that the subdimension perceived positive most is the peer support. Our study is not in congruence with the literature. The average scores of surgical nurses, participating in our study, on the scale of individual workload perception is $73.37 \pm 9.06$. Considering the fact that the scale ranges between 31 and 155, this result shows that the individual workload perception of surgical nurses is within the normal level. Tan et al (2012) identified in their study that the nurses have a high working environment perception. Our study is not similar to the literature.

The average score of nurses, participating in our study, on the occupational stress scale is $40.86 \pm 5.40$. Taking into consideration that the scale ranges from 18 to 72, the surgical nurses have a medium level occupational stress. Kopuz (2013) determined in her study that the nurses' score on the occupational stress is $38.89 \pm 8.92$. The nurses' score on the occupational stress is found as $40.77 \pm 682$ in Ercevik's (2010) study. Our study is in congruence with the literature. The average score of surgical nurses, participating in our study, on the scale of medical error attitude is $42.21 \pm 4.99$. Considering the fact that the scale ranges between 16 and 80, the surgical nurses perceive the medical error attitude scale at the medium level. Gulec (2012) as certained in the study that the nurses are more positive in reporting the medical error as the latter occurs. Dikmen at al (2014) and Cebeci et al (2012) identified in their studies that the nurses have low score on the proneness to medical error. Our study is not in accordance with the literature.

Any statistically significant association is not discovered between the total scores on the scales of individual workload perception, occupational stress, and medical error attitude. As Kopuz (2013) stated in 
her study that the optimistic approach decreases, obedient approach increases, and seeking a social support decreases, when the occupational stress increases. Saygilı and Celik (2011) asserted in their study that the rise of workload leads the treatment and care to be interrupted, distraction, medical errors to be made.

\section{Conclusion}

It was identified that the overall average scores of surgical nurses on the scales of individual workload perception, occupational stress, and medical error attitude are directly proportional.

The facts that no association is found between the scales employed in our study; the surgical nurses' overall scores and average scores on the subdimensions of the scale of individual workload perception are within the normal level; the surgical nurses experiencing a medium level occupational stress have a positive medical error attitude lead us to think that any significant association is not found between them. As the subscale score of executive support of individual workload perception scale increases in surgical nurses, peer support and unit support score also increase. As the unit support score increases, so does the work environment score. The involuntary employees' job-related tension scale score in the service was significantly higher than the willing and partially willing employees. The difference between individual workload perception scale, work-related tension scale, attitude scale in medical errors and other independent variables was not statistically significant.

Mean score of the intention to carry out the current job of the individual workload perception scale in surgical nurses is more negative in nurses between 19-30 age group. The average score of the peer support subscale of the individual workload perception scale was higher in male nurses. The average score of peer support subscale of individual workload perception scale is higher in surgical nurses who do their job voluntarily.

The overall average scores of surgical nurses on the scales of individual workload perception, occupational stress, and medical error attitude are directly proportional.
Ethics Committee Approval: Ethics committee approval was received for this study from Clinical Research Ethics Committee of Ordu University. (Decision Number: 12.02.2016-2016/2)

Peer-review: Externally peer-reviewed.

Author Contributions: Concept-N.B.; Design-N.B., Y.Ö.; Materials- N.B., Y.Ö.; Data Collection and/or Processing-Y.Ö.; Literature Review-Y.Ö., WritingY.Ö., N.B., Critical Review-N.B., D.Ç., Y.Ö.

Conflict of Interest: No conflict of interest was declared by the authors.

Financial Disclosure: The authors declared that this study hasn't received no financial support.

\section{References}

Aytac S. Chronic stress sources in the workplace. Journal of Jop Power Industrial Relations and Human Resources; 2002;4(1), 276.

Alcelik A, Deniz F, Yesildal N, Mayda AS, Serifi BA. Evaluation of health problems and life habits of nurses working in AIBU Medical Faculty Hospital. TSK Preventive Medicine Bulletin; 2005;4(2), 55-65.

Anezz E. Clinical perspectives on patient safety research in to practice, 1st Ed. London, Mcgraw Hill Education Open University Press. 2006;9-18.

Anderson B, Stumpf PG, Schulkin J. Medical error reporting, patient safety, and the Physician. Journal of Patient Safety;2009; 5(3), 176-179.

Aslan SH, Alparslan NZ, Aslan OR, Kespare C, Unal M. Validity and reliability of work-related stress scale among healthcare workers. Thinking Man;1998;11(2), 4-8.

Arıkan, D., Karabulut, N. Determining nursingrelated tension and factors affecting this. Atatürk University Journal of School of Nursing; 7(1), 1012.

Ayaz S, Beydag KD. (2014). Factors affecting nurses' quality of work life: Balıkesir case. Journal of Health and Nursing Management; 2014;2(1), 6668.

Balcik E. Nurses' perception of structural strengthening and job-related tension levels. Haliç University, Faculty of Health Sciences, Master's Thesis, İstanbul. 2013.

Cebeci F, Gursoy E, Tekingunduz S. Determining the tendency of nurses to make medical error. Anatolian Journal of Nursing and Health Sciences;2012;15(3), 188-195. 
Cox KS, Teasley SL, Lacey SR, Sexton KA, Carroll CA. Work environment perceptions of pediatric nurses. Journal of Pediatric Nursing; 2007;22(1), 179-182.

Dagget T, Molla A, Belachew T. Job related stress among nurses working in Jimma Zonepublic hospitals, South West Ethiopia: a cross sectional study. BMC Nursing; 2016;15(39), 1-10.

Dikmen DY, Yorgun S, Yesilcam N. Determining the tendency of nurses to medical errors. Hacettepe University Journal of Nursing;2014; 44-56.

Er F, Altuntas S. Hemşirelerin tıbbi hata yapma durumları ve nedenlerine yönelik görüşlerinin belirlenmesi. Journal of Health and Nursing Management; 2016;3(3),132-139.

Ercevik R. Job related stress, burnout levels and affecting factors in nurses. Haliç University, Faculty of Health Sciences, Master's Thesis, İstanbul. 2010.

Eroglu E. Determination of the impact of workload on patient safety in a training and research hospital. At1lım University, Faculty of Health Sciences, Master's Thesis, Ankara. 2011

Eser I, Khorshid L, Turk G, Toros F. To determine the factors that may cause nurses to make drug mistakes. Journal of School Nursing Ege University; 2007;23(2):81-91

Gulec D, Indepeler S. Developing a scale of attitudes towards medical errors. Hemşirelikte Araştırma Dergisi; 2013;15(3):26-41

Gunes U, Gurlek O, Sonmez M. Factors contributing to medication errors in Turkey: Nurses' perspectives. Journal of Nursing Management; 2014;22, 295-303.

Hillin E, Hicks RW. Medication errors from an emergency room setting: Safety solution for nurses. Critical Care Nursing Clinics of North America;2010;22(2), 91-96.

Hongxia G, Chunping N, Cnangqing L, Jiping L, Suzhen L. Perceived job stress among community nurses: A multi-center cross-sectional study. International Journal of Nursing Practice 2019;25(1), 1-8.

Hughes RG, Ortiz E. Medication errors: why they happen and how they can be prevented. Journal of Infusion Nursing; 2005;28(2), 14-24.

Intepeler SŞ, Dursun M. Medical errors and medical error reporting systems. Anatolian Journal of Nursing and Health Sciences; 2012;15(2), 129135.
Joint Commission on Accreditation of Healthcare Organizations. Sentinel event statistics. ABD, Erişim:

16.06.2015.http://www.Jointcommissioninternati onal.Org/International-Essentials- $\quad$ ForQualityand-2006.

Kebapci A, Akyolcu N. The effect of working environment on burnout levels in nurses working in emergency units. Turkey Journal of Emergency Medicine; 2011;11(2), 59-67.

Kopuz E. Determining the level of work-related tension of nurses and examining the attitudes of coping with stress. Haliç University, Faculty of Health Sciences, Master's Thesis, İstanbul. 2013.

Mohsen AH, Marzieh K, Negin MA. Nurses' perception of occupational stress and its influencing factors: A qualitative study. Iran $\mathbf{J}$ Nurs Midwifery Res. 2012;17(5): 352-359.

Mollaoglu M, Fertelli TK, Tuncay FO. Evaluation of the perceptions of the nurses working in the hospital. Firat Journal of Health Services; 2010;5(15), 17-30.

Nguyen EE, Connolly PM, Wong V. Medication safety initiative in reducing medication errors. Journal of Nursing Care Quality; 2010;25(3), 224-230.

Ozata M, Altunkan H. Determining the frequency of medical errors, types of medical errors and causes of medical errors in hospitals: Konya Case. Journal of Medical Research; 2010;8 (2), 100-111.

Parlar S. A disregarded situation in health care workers: Healthy working environment. TAF Preventive Medicine Bulletin; 2008;7(6), 547554.

Parshuram CS, To T, Seto W, Trope A, Koren G, Laupacis A. Systematic evaluation of errors occurring during the preparation of intravenous medication. CMAJ; 2008;178(1), 42-48.

Sayek F. Patient Safety: Turkey and the world. TTB Reports / Books. 1st. Ed. Çakmakçı M, Akalın HE. Ankara, 2011;17-19.

Saygili M, Celik Y. Evaluating the relationship between job satisfaction and perceptions of hospital employees about their working environments. Hacettepe Journal of Health Administration; 2011;14(1), 40-44.

Sheu SJ, Wei IL, Chen CH, Yu S, Tang FI. Using snowball sampling method with nurses to understand medication administtration errors. Journal of Clinical Nursing; 2008;3(1), 1-12.

Tan M, Polat H, Sahin ZA. Evaluation of nurses' perceptions about work environments. Journal of Performance and Quality in Health; 2012;4(1), 6778. 
Tang FI, Sheu SJ, Yu S, Wei IL, Chen CH. Nurses relate the contributing factors involved in medication errors. Journal of Clinical Nursing; 2007;16(3), 447-57.

Tel H, Aydin TH, Karabey G, Vergi I, Akay D. Dealing with stress and stress related to work in nurses. Journal of Nursing Cumhuriyet; 2012;2, 47-52.

Tunaligil V. Comparison of job-related tension and burnout indicators in emergency medical technicians working in public and private ambulances. İstanbul University, Faculty of Health Sciences, PhD Thesis, İstanbul. 2013.

Yang T, Guo Y, Ma M, Li Y, Tian H, and Deng J. Job stress and presenteeism among Chinese healthcare workers: The mediatingeffects of affective commitment. International Journal of Environmental Research and Public Health; 2017;14(9), 978.

Yigitsoy M. Determination of drug application errors and causes of nurses. Near East University, Faculty of Health Sciences, Master's Thesis, Lefkoşa/KKTC.2014

Wright K. Do calculation errors by nurses cause medication errors in clinical practice? A literature review. Nurse Education Today; 2010;30(1), 8597. 